\title{
Traction Motor Sizing for Optimal Fuel Economy in Propulsion Hybridization
}

\author{
Y. Gene Liao ${ }^{*}, 1$ and Allen M. Quail, Jr. ${ }^{2}$ \\ ${ }^{I}$ Wayne State University, Detroit, Michigan, USA \\ ${ }^{2}$ ASRC-WTSI, Inc., Troy, Michigan, USA
}

\begin{abstract}
This paper presents the traction motor sizing for optimal urban fuel economy in two mild and three strong hybridization propulsion on front-wheel-drive vehicles. The traction motor sizes, by means of motor rated torque and speed, are optimized for maximum urban fuel economy. The two mild hybrids are Belt-Integrated-Starter-Generator (BISG) and Crankshaft-Integrated-Starter-Generator (C-ISG) systems. The three strong hybrid configurations include a strong C-ISG system where motor is placed between a starting clutch and the transmission, one-mode Electric Variable Transmission (EVT), and two-mode EVT. Using the simulated vehicle performance data as constraints and the motor rated torque and speed as the design variables, the objective function is to maximize the urban fuel economy. The purpose of this study is to provide a design guideline for hybrid propulsion configurations and component sizing of the traction motors.
\end{abstract}

Keywords: Component sizing, Electric-variable-transmission, EVT, Hybrid electric vehicle, ISG, Traction motor.

\section{INTRODUCTION}

Hybrid propulsion systems provide an additional control dimension, as they can control not only engine speed but also the fraction of engine power that is transferred to the driving wheels. This additional level of control enables fuel economy improvement by adding operation features not available with conventional powertrains [1-3]. The Hybrid Electric Vehicle (HEV) can be propelled via the internal combustion engine (ICE), the electric motor, or both. At low speeds when little power is needed, the vehicle moves along silently on just electric power. As the driver accelerates, more power is needed and the engine automatically starts, providing additional power. At cruising speeds, the engine runs alone, driving the electric machine and charging the batteries if needed. The electric motor engages for aggressive acceleration as needed. While braking, electricity gets generated and stored in the batteries for use with the electric motor (regenerative braking). The above features are described next.

The first operation feature enabled by hybridization is that the engine can be turned off when idling or during periods of low power output - two highly inefficient stages of typical ICE operation. This feature is used when engine load is low and operates at a highly inefficient level, such as in deceleration and vehicle launch stages. The vehicle accessories, such as power steering and air conditioning, are electrically powered to maintain the auxiliary functions during engine turn-off stage. The vehicle is propelled by the electric system in the launch stage (assuming that the battery is sufficiently charged). The second hybrid operational feature that can increase fuel economy is electric machine

*Address correspondence to this author at the Division of Engineering Technology, Wayne State University, Detroit, Michigan 48202, USA; Tel: 313-577-8078; Fax: 313-577-1781; E-mail: geneliao@wayne.edu power assist. This assist function has two primary elements. The first element provides assist during varying power demand. This function enables a more fuel-efficient transmission calibration because the required amount of reserve engine power needed for pleasing operation is reduced. The second element of power assist is engine downsizing. During peak demand, the electric machine augments engine power thereby allowing a smaller engine to provide similar performance as a larger engine. Reducing the size of the engine improves fuel economy since the engine operates at a higher percentage of its peak capacity more of the time. Finally, hybrid systems can improve fuel economy by allowing the recuperation of vehicle kinetic energy into stored electrical energy during deceleration or braking actions. When the driver lifts a foot off the accelerator, the electric motor slows the vehicle and at the same time acts as a generator, recharging the battery pack. When the brake is applied, the electric motor actually slows the vehicle while it also charges the battery pack. As additional braking torque is needed, the traditional frictional brakes take over. This recapture energy can be used at a later time to power the auxiliaries or propel the vehicle instead of being lost to heat in the brake rotors.

A hybrid propulsion is comprised of electric motors with power electronics, energy storage devices such as batteries and ultracapacitors, and sophisticated controllers, in addition to such classical components as internal combustion engines, transmissions, clutch, drive shafts, differentials, etc. Therefore, hybrid propulsion is much more complicated than a conventional powertrain. The drivetrain configuration, energy balance optimization, and component optimal sizing have been the focus of research and development in hybrid vehicles in both academic community and industry. Sizing the traction motor is a key point in a HEV to improve fuel economy and dynamic performances $[4,5]$. The process of selecting the appropriate electric propulsion systems is however difficult and should be carried out at the system 
level. The objective of this paper is to optimize the traction motor sizes, by means of motor rated torque and speed, such that the fuel economy of the urban driving cycle is maximized. The vehicle fuel economy and performance of two mild and three strong hybridization propulsions on frontwheel-drive vehicles are first simulated. Using the simulated vehicle performance data as constraints and the motor rated torque and speed as the design variables, the objective function is to maximize the urban fuel economy.

\section{PROPULSION HYBRIDIZATION}

In a typical vehicle drive train system, four primary components are engine, transmission, final drive and axle, and drive wheels. The engine's primary function is to supply power to the other components of the system. The transmission controls the speed ratio and the level of torque multiplication between the engine and the final drive. The final drive and drive axle assembly multiplies transmission output torque and transfers power to the wheel assembly. Finally the tire and wheel assembly transfers power from the axle to ground. To hybridize a vehicle propulsion system, electric machine must be connected somewhere in the power flow. Based on the ratio of electric power to total power of a vehicle, the degree of propulsion hybridization $[6,7]$ is typically classified into two levels: mild and strong (or full) hybrids. The front-wheel-drive vehicle in which engine drives the primary front axle is selected in this study.

\subsection{Mild Hybrid}

The mild hybrids provide limited functions, such as engine stop/start and regenerative braking energy capture. The "mild" means that the vehicle uses a relatively small motor for torque assist of the engine. Belt-Alternator-Starter (BAS) system $[8,9]$ or Belt-Integrated-Starter-Generator (BISG) [10] and Flywheel-Alternator-Starter (FAS) [11], Crankshaft-Integrated-Starter-Generator (C-ISG) [12], or Integrated-Motor-Assist (IMA) systems [13, 14] are currently available mild hybrid propulsions. The B-ISG system replaces the standard alternator with an electric motor/ generator that is connected to the ICE via a belt or chain. The system enables early fuel cut-off during deceleration and shut off of the engine during idle. It operates in two modes: (1) motoring - provides cranking torque to restart the engine when the brake pedal is released and to assist vehicle aceleration; (2) generating - charges the battery when the engine is running. The battery provides electric power to run vehicle accessories and passenger comfort systems while the engine is off. Regenerative braking capabilities are also included to further enhance fuel economy. The B-ISG system strikes a compromise between fuel efficiency and price. It is designed to fit in the same space as a typical engine and work with conventional transmissions to minimize integration effort and cost. Fig. (1) illustrates a typical B-ISG system layout.

The C-ISG system replaces the conventional starter motor and alternator with a larger (than in B-ISG) electric machine located between the engine flywheel and transmission. The C-ISG has the similar functions as the B-ISG. A C-ISG system typically utilizes conventional transmissions with significant packaging changes to accommodate



(a) Layout of front engine accessory drive



(b) Assembly of ISG and power electronics box

Fig. (1). Layout of a typical B-ISG system [9].

the increased envelope of the electric machine. The electric machine in the C-ISG system may be packaged around torque converter (using a ring type motor) such as [12], or between the engine and the transmission where the torque converter is removed, such as in Honda IMA system [13, 14]. The C-ISG systems can be changed from mild to strong hybridization by adding starter clutch and increasing the power rating of the electric machine and the corresponding battery capacity [15]. Fig. (2a) and (2b) respectively shows the mild and strong C-ISG systems.

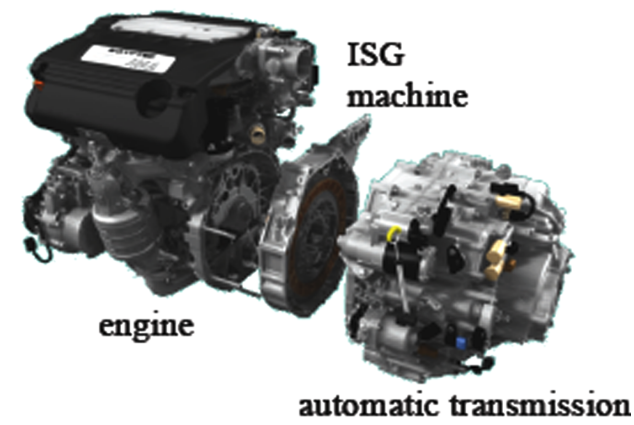

(a) Mild C-ISG

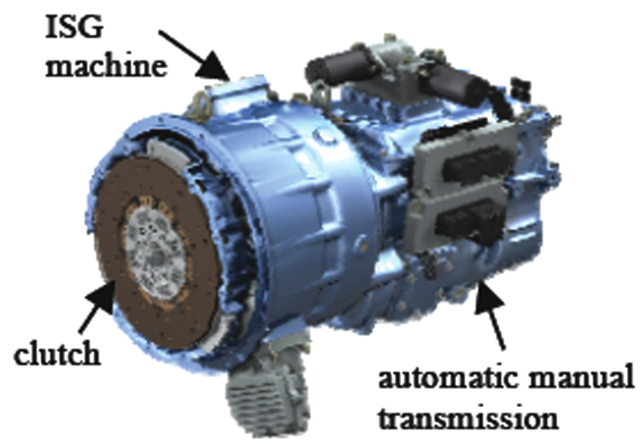

(b) Strong C-ISG

Fig. (2). Layout of a typical C-ISG system [14, 15]. 


\subsection{Strong or Full Hybrid}

In addition to enhancing the features of a mild hybrid, the electric motor used in full hybrid architectures provides a larger percentage of total power for longer durations. They also enable electric-only launch and the capability to run solely in electric mode at lower speeds (including reverse) without engaging the ICE. This enables higher levels of fuel efficiency. Three strong hybridization vehicle propulsions are presented and considered in this study. The first configuration is a strong C-ISG system, where motor is packaged between a starting clutch and the transmission. The other two configurations are one-mode Electric-Variable-Transmission (EVT) and two-mode EVT.

The strong C-ISG configuration is attractive because one electric machine can be used to start the engine, to propel the vehicle, and to be function as generator. Fig. (3a) illustrates that motor is connected to the transmission input shaft and takes advantage of the torque multiplication of the transmission. The engine is connected to the drive train via a starting clutch. The vehicle may be launched with the motor only where the starting clutch is disengaged and the engine may be turned off or it may be left idling. If the engine participates in the launch, the starting clutch will slip until the transmission input shaft is synchronized with the engine speed. During deceleration, the motor/generator regenerates braking energy to the battery. The engine may be disconnected from the transmission for maximum regeneration or it may be left connected for ease of control. Eaton hybrid drive unit [15] is a strong C-ISG system coupled with automated manual transmissions that have been implemented in production city buses and medium-duty trucks.

The EVT combines planetary gear sets with electric machines and clutches to eliminate the use of a conventional transmission. The one-mode EVT is the major framework of the hybrid fleet from Toyota, Ford and Nissan [16-18]. Another major EVT design on the market is the Allison Hybrid System, also known as AHSII [19]. This system as a two-mode system is applied to several mid-sized SUV's and pickup trucks [20]. A one-mode EVT, shown in Fig. (3b) and (3c) [21], is studied in this project. The mode means a range of infinitely variable gear ratios. The one-mode is an input split mode that is used for launching the vehicle from a stop or driving at low speeds $[17,22]$. The input power split is a parallel hybrid which uses planetary gear set to divide the engine power into an electrical path and a mechanical path. The planetary gear set multiplies engine torque and allows the engine to operate over a continuous range of
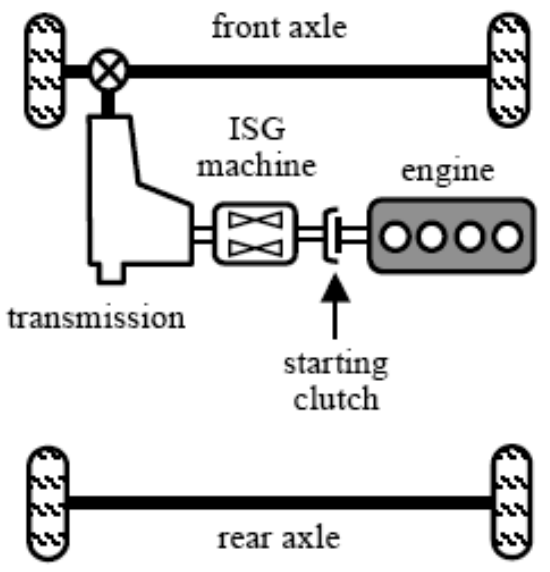

(a) C-ISG with starting clutch

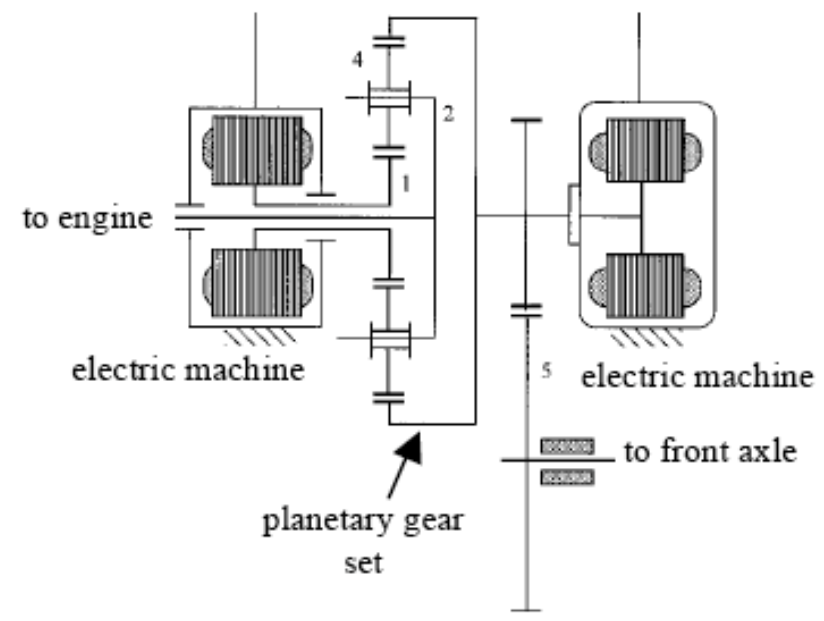

(c) Layout of one-mode EVT [21]



(b) One-mode EVT

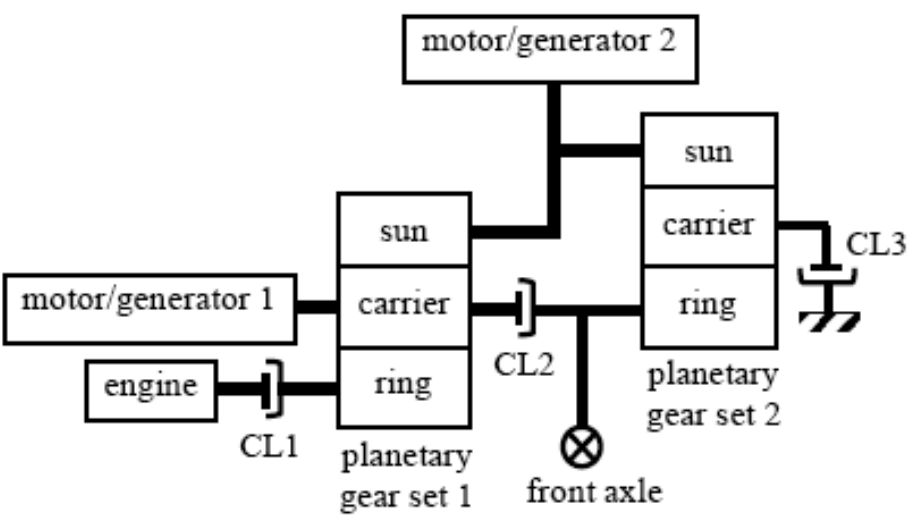

(d) Layout of two-mode EVT [23]

Fig. (3). Configurations of three strong HEVs. 
speeds. This architecture utilizes a power-flow where the engine is connected to a planetary carrier (input 1), a generator is connected to the corresponding sun gear (input 2 ), and another electric motor is connected on the ring gear (transmission output). This configuration allows a great deal of engine control flexibility and also provides full hybrid functionality.

The two-mode EVT for front-wheel-drive vehicle consists of two planetary gear sets and three clutches as shown in Fig. (3d) [23]. By selectively engaging and disengaging of the clutches, the compound input power split EVT establishes different torque multiplication ratios between the engine, electric motors and transmission output shaft. This allows for additional flexibility and better performance with the same size electrical components. The first and second planetary gear sets split mechanical power from the input. The first mode of the power-split (Mode 1) exists when the output shaft is driven by the planetary gear set 2 where CL3 is applied, and the second mode (Mode 2) exists when the output shaft is driven by the planetary gear set 1 and CL2 is on. The electric launch of the vehicle has two regions that depend on the vehicle velocity, and the engine is always off (CL1 off). The first region is for low speeds (CL1 and CL2 are off, CL3 is on, and motor/generator 2 is on while motor/ generator 1 is off), the second region (CL1 is off, CL2 and CL3 are on, and both electric machines are motoring) is for faster speeds. As significant transmission power is required: the engine is on (CL1 is on or engaged) and there is power flow from the battery pack. At low speeds, Mode 1 is selected and then Mode 2 is selected as fast speeds are attained. The continuous variable gear ratio regime has engine power and no power flow to or from the battery pack, and occurs when the vehicle road load is relatively small. When the vehicle is moving slowly in this regime, Mode 1 is chosen; when the vehicle is moving at medium or fast speeds, Mode 2 is selected.

This paper investigates the traction motor sizing for optimal urban fuel economy in two mild hybrids (B-ISG and C-ISG) and three strong hybrid configurations (strong $\mathrm{C}$ ISG, one- and two-mode EVT).

\section{HEV MODELING AND SIMULATION}

The component sizing and system prototyping of a hybrid propulsion is difficult because of the many design options and the rapidly developing technologies in the automotive industries. Modeling and simulation is needed to analyze component sizing and quantify benefits of hybrid propulsion configurations. Vehicle simulation model can be generally classified as two types: kinematic and dynamic methods. In the kinematic method, the force required to accelerate the vehicle through the time step is calculated directly from the required speed trace. The required force is then translated into a torque that must be provided by the component directly upstream. This power/energy requirement at the wheel is passed backward through all the propulsion components to compute fuel and electricity consumption. The dynamic method is solved forward approach where the desired vehicle speed is an input to the driver/PID controller which actuates the accelerator position therefore requesting torque from the engine which in turn produces a response through the driveline. This method is more realistic in that it controls the engine similar to the way an actual driver does and does not impose or directly control the driveline components. The adjustment of the driver/PID determines how accurately the analytical vehicle follows the desired vehicle speed trace. The dynamic method was applied in this project.

The GT-Drive software [24] was used for the analytical simulation in this project. For this study, a relatively simple approach was taken that uses steady state engine performance maps to determine fuel rate for a desired engine torque at a given engine speed. It has been shown that fuel economy can be accurately predicted using simple steady state engine maps $[25,26]$. For accurate simulation, the model requires considerable driveline information: clutch and torque converter performance tables; transmission with gear ratios, inertias, efficiencies and shift schedule; drive shaft and axle with inertias; final drive with gear ratio and inertias; tires with radius, rolling resistances; brake with braking torque maps; and any other data related to vehicle resistances such as aerodynamic loading. Other control algorithms were added to the model for simulating an idle speed controller and a simple fuel shutoff control during deceleration events. A GT-Drive vehicle model with one-mode EVT is presented in Fig. (4). Fig. (4a and $\mathbf{4 b}$ ) respectively shows the vehicle and powertrain model.

The fuel economy prediction is based on the U.S. Environmental Protection Agency (EPA) drive schedule. The EPA drive schedule is divided into two main portions: urban and highway drive cycles respectively represented by FTP-75 (Federal Test Procedure) and HWFET (Highway Fuel Economy Test) [27]. The urban cycle contains lower vehicle speeds and more stop and go (or accelerating, decelerating, and idle). Cold start fuel penalty also applies to urban cycle. The highway cycle represents freeway conditions and contains higher vehicle speeds and more steady state cruise regions. These two cycles are combined into a formula, as illustrated in Eq. (1), to obtain the composite fuel economy value. The composite fuel economy is defined as:

1
$\frac{0.55}{\text { urban fuel economy }}+\frac{0.45}{\text { highway fuel economy }}$$\cdots$

The label numbers that appear on the vehicle stickers are adjusted by the EPA to represent fuel economy closer to on the road conditions.

Adjusted or label urban fuel economy $=$ Simulated or test of urban fuel economy*0.9 ...

Adjusted or label highway fuel economy $=$ Simulated or test of highway fuel economy* $0.78 \ldots$

In this paper, all the fuel economy data are converted to adjusted data. Additional to the fuel economy data, vehicle performance data is also important. The standard performance categories are vehicle maximum velocity and peak aceleration, time to peak acceleration, time to reach 48 kilometer per hour (kph), time to reach $96 \mathrm{kph}$, time to reach $128.7 \mathrm{kph}$ from $80.5 \mathrm{kph}$, and gradeability at $88.5 \mathrm{kph}$. 


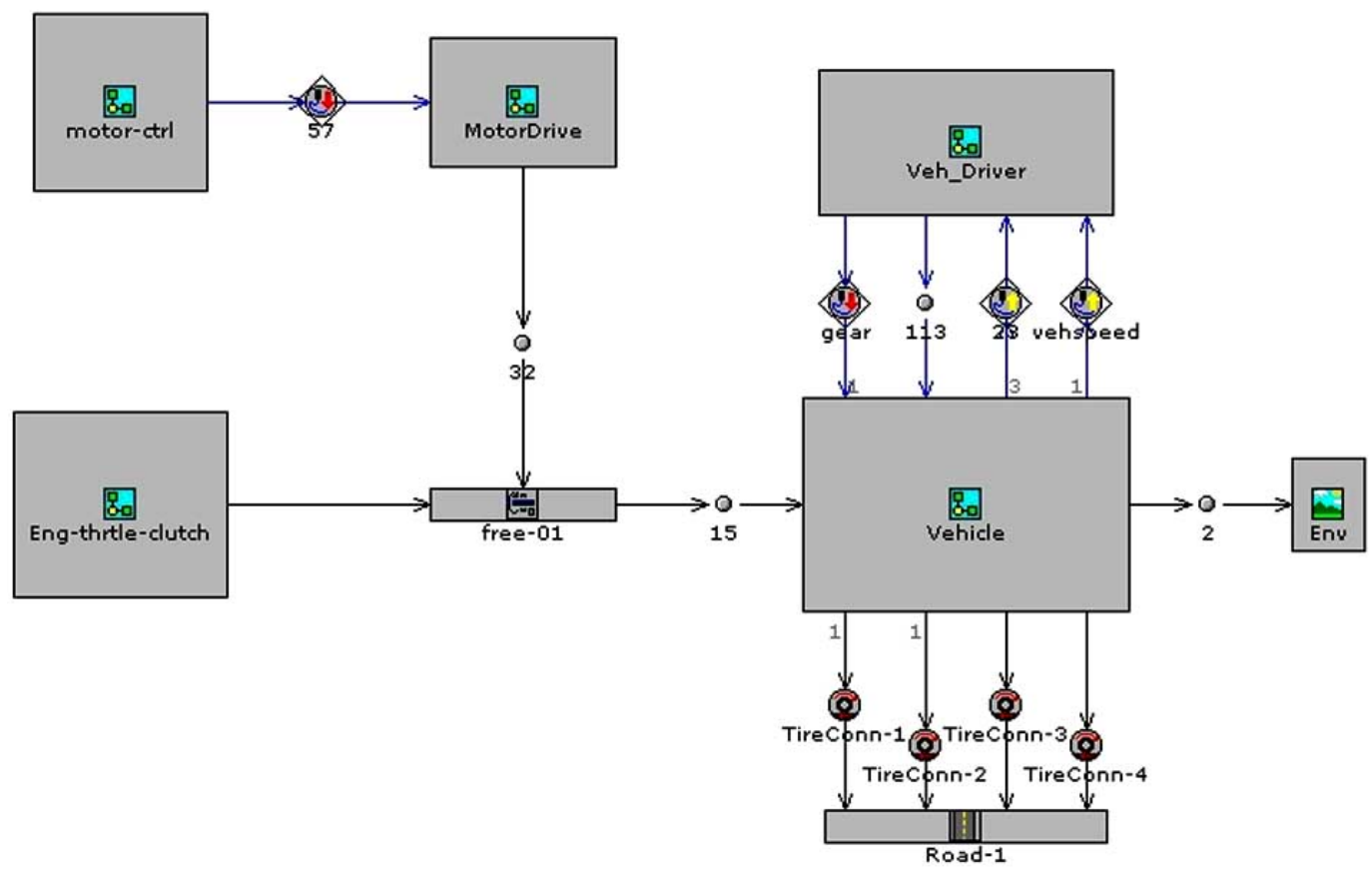

(a) Vehicle system model

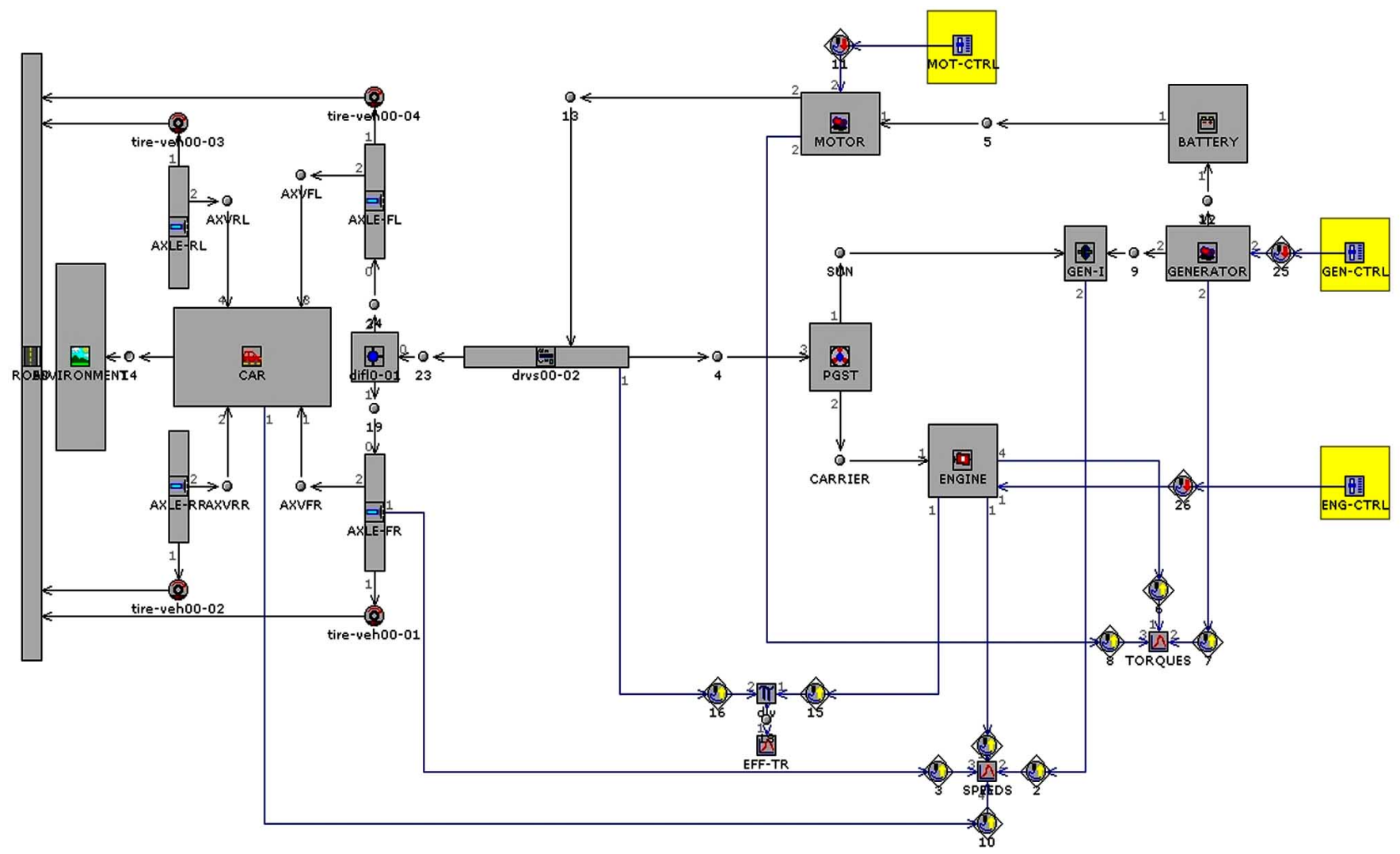

(b) One-mode EVT powertrain model

Fig. (4). Layout of a GT-Drive model.

\subsection{Conventional Vehicle Analysis}

The fuel economy and vehicle performance of conventional powertrain, two mild, and three strong hybrid configu- rations are predicted using GT-Drive software. The purpose of conventional vehicle analysis is to validate the simulation model and to use the simulated results as a baseline for gauging the vehicle fuel economy and performance of the 
HEVs. The base vehicle is a front-wheel-drive compact size sport utility vehicle equipped with an inline four-cylinder 2.2-liter engine $(102 \mathrm{~kW}$ at $5200 \mathrm{rpm}$ and $198 \mathrm{~N}-\mathrm{m}$ at 4400 $\mathrm{rpm}$ ), CVT (ratio range from 2.63 to 0.47 ), and 4.98 final drive ratio. The vehicle mass is $1588 \mathrm{~kg}$ with aerodynamic characteristics as: $2.59 \mathrm{~m}^{2}$ frontal area, 0.397 drag coefficient, and $1.2555 \mathrm{~kg} / \mathrm{m}^{3}$ air density. The simulated urban fuel economy is 22.2 mile per gallon (mpg) or 10.59 liter $/ 100 \mathrm{~km}$, which is $5.6 \%$ higher than the test vehicle data or label data (21 mpg or 11.2 liter $/ 100 \mathrm{~km}$ ). The simulated highway fuel economy is $28.2 \mathrm{mpg}(8.34 \mathrm{liter} / 100 \mathrm{~km})$, which is $0.7 \%$ higher than the test vehicle data $(28 \mathrm{mpg}$ or 8.4 liter $/ 100 \mathrm{~km})$. Therefore the composite fuel economy is $24.6 \mathrm{mpg}(9.56$ liter $/ 100 \mathrm{~km}$ ) and $2.5 \%$ higher than label data $(24 \mathrm{mpg}$ or 9.8 liter $/ 100 \mathrm{~km}$ ). Based on this correlation, the predicted fuel economy is acceptable. The fuel economy improvements on hybrid vehicles will use these simulation data (on conventional vehicle) as a comparison base. The predicted vehicle performance is: $184.2 \mathrm{kph}$ vehicle top speed, $3.81 \mathrm{~m} / \mathrm{s}^{2}(0.39$ g) peak acceleration, $1.8 \mathrm{sec}$ to the peak acceleration, $4.3 \mathrm{sec}$ to reach $48 \mathrm{kph}, 9.6 \mathrm{sec}$ to reach $96 \mathrm{kph}, 9.0 \mathrm{sec}$ to reach $128.7 \mathrm{kph}$ from $80.5 \mathrm{kph}$, and $20.8 \%$ gradeability at 88.5 $\mathrm{kph}$.

\subsection{B-ISG (Mild Hybrid) Analysis}

The engine, transmission, torque converter and final drive ratio are identical to conventional vehicle in the B-ISG configuration. The hybrid vehicle mass is $1688 \mathrm{~kg}$ which adds $100 \mathrm{~kg}$ for hybrid components. For comparison purpose, the aerodynamic characteristics are the same as conventional vehicle. The hybrid components include an inverter, battery (36 Volt, 20 amp-hrs, $4.7 \mathrm{~kW} \max$ power charge and $8.4 \mathrm{~kW}$ max power discharge) and one electric machine (induction motor, $4.0 \mathrm{~kW}$ rated power, $10000 \mathrm{rpm}$ rated speed, and $70 \mathrm{~N}-\mathrm{m}$ rated torque). The belt ratio between motor and crankshaft is 1.60 .

The simulated urban fuel economy is $24.3 \mathrm{mpg}(9.68$ liter $/ 100 \mathrm{~km}$ ), which is $9.4 \%$ improvement over the conventional vehicle $(22.2 \mathrm{mpg}$ or $10.59 \mathrm{liter} / 100 \mathrm{~km})$. The simulated highway fuel economy is $28.4 \mathrm{mpg}$ (8.28 liter/100km), which is only $0.7 \%$ improvement over the conventional vehicle $(28.2 \mathrm{mpg}$ or 8.34 liter $/ 100 \mathrm{~km})$. Therefore the composite fuel economy is $26.0 \mathrm{mpg}(9.05$ liter $/ 100 \mathrm{~km})$ and $5.7 \%$ improvement $(24.6 \mathrm{mpg}$ or $9.56 \mathrm{liter} / 100 \mathrm{~km})$. The predicted vehicle performance is: $179 \mathrm{kph}$ vehicle top speed, $3.60 \mathrm{~m} / \mathrm{s}^{2}(0.37 \mathrm{~g})$ peak acceleration, $2.2 \mathrm{sec}$ to peak aceleration, $4.3 \mathrm{sec}$ to reach $48 \mathrm{kph}, 10.2 \mathrm{sec}$ to reach $96 \mathrm{kph}$, $10.2 \mathrm{sec}$ to reach $128.7 \mathrm{kph}$ from $80.5 \mathrm{kph}$, and $18.4 \%$ gradeability at $88.5 \mathrm{kph}$.

\subsection{C-ISG (Mild Hybrid) Analysis}

The C-ISG mild hybrid vehicle mass is $1688 \mathrm{~kg}$ which adds $100 \mathrm{~kg}$ for hybrid components. For comparison purpose, the aerodynamic characteristics are the same as conventional vehicle. The hybrid components include an inverter, battery (42 Volt, $55 \mathrm{amp}-\mathrm{hrs}, 8 \mathrm{~kW}$ max power charge and $12 \mathrm{~kW}$ max power discharge) and one electric machine (induction motor, $7.0 \mathrm{~kW}$ rated power, $10000 \mathrm{rpm}$ rated speed, and $123 \mathrm{~N}-\mathrm{m}$ rated torque). The motor is directly mounted to the engine flywheel, therefore the ratio is 1.00 .
The simulated urban fuel economy is $25.0 \mathrm{mpg}(9.41$ liter $/ 100 \mathrm{~km}$ ), which is $12.6 \%$ improvement over the conventional vehicle. The simulated highway fuel economy is 28.7 mpg (8.19 liter $/ 100 \mathrm{~km})$, which is only $1.8 \%$ improvement over the conventional vehicle. Therefore the composite fuel economy is $26.6 \mathrm{mpg}$ (8.84 liter $/ 100 \mathrm{~km})$ and $8.2 \%$ improvement. The predicted vehicle performance is: $179 \mathrm{kph}$ vehicle top speed, $3.61 \mathrm{~m} / \mathrm{s}^{2}(0.37 \mathrm{~g})$ peak acceleration, $2.7 \mathrm{sec}$ to peak acceleration, $4.3 \mathrm{sec}$ to reach $48 \mathrm{kph}, 10.1 \mathrm{sec}$ to reach $96 \mathrm{kph}, 10.1 \mathrm{sec}$ to reach $128.7 \mathrm{kph}$ from $80.5 \mathrm{kph}$, and $18.5 \%$ gradeability at $88.5 \mathrm{kph}$.

\subsection{Strong C-ISG Analysis}

The engine, transmission, and final drive ratio are identical to conventional vehicle for the strong C-ISG architecture. The torque converter is replaced by a starting clutch. For comparison purpose, the aerodynamic characteristics are the same as the conventional vehicle. The hybrid vehicle mass is $1738 \mathrm{~kg}$ which adds $150 \mathrm{~kg}$ for hybrid components. The hybrid components include an inverter, battery (300 Volt, $6.5 \mathrm{amp}-\mathrm{hrs}, 20 \mathrm{~kW} \max$ power charge and $28 \mathrm{~kW} \max$ power discharge) and one electric machine $(20.9 \mathrm{~kW}$ rated power, $14000 \mathrm{rpm}$ rated speed, and $90 \mathrm{~N}-\mathrm{m}$ rated torque). The energy management and control strategy are the same as [6].

The simulated fuel economy is $32.7 \mathrm{mpg}$ (7.19 liter/ $100 \mathrm{~km})$ in urban (47.2\% improvement) and $28.9 \mathrm{mpg}(8.14$ liter $/ 100 \mathrm{~km})$ in highway $(2.5 \%$ improvement $)$, which results in $30.9 \mathrm{mpg}$ (7.61 liter $/ 100 \mathrm{~km})$ composite fuel economy (25.5\% improvement). The predicted vehicle performance is: $178.8 \mathrm{kph}$ vehicle top speed, $3.51 \mathrm{~m} / \mathrm{s}^{2}(0.36 \mathrm{~g})$ peak acceleration, $2.3 \mathrm{sec}$ to peak acceleration, $3.8 \mathrm{sec}$ to reach 48 $\mathrm{kph}, 9.9 \mathrm{sec}$ to reach $96 \mathrm{kph}, 10.4 \mathrm{sec}$ to reach $128.7 \mathrm{kph}$ from $80.5 \mathrm{kph}$, and $18.0 \%$ gradeability at $88.5 \mathrm{kph}$.

\subsection{One-Mode EVT Analysis}

In the one-mode EVT, the engine and final drive ratio are identical to conventional vehicle. The hybrid components include two inverters, battery (300 Volt, $6.5 \mathrm{amp}-\mathrm{hrs}, 20 \mathrm{~kW}$ max power charge and $28 \mathrm{~kW}$ max power discharge), two electric machines $(25.1 \mathrm{~kW}$ rated power, $14000 \mathrm{rpm}$ rated speed, and $90 \mathrm{~N}-\mathrm{m}$ rated torque), and one planetary gear set (2.21 ratio) with clutches. A gear ratio of 2.21 is connected to motor because motor rotates faster than planetary output shaft. The energy management and controls are similar to the previous two configurations with the following modifications:

- Engine Control Strategy: load following with battery assist. The engine operates at the lowest possible speed with the battery assisting if required.

- Instantaneous Optimization Method: lowest system loss. The valid engine speed and torque range is analyzed at each time step, and the torque combination resulting in the lowest total system loss is selected [28].

The total system loss represents the overall driving efficiency of the vehicle and is calculated as:

Total system loss $=w_{e} *$ engine loss $+w_{m} *$ electric machine losses $+w_{t} *$ transmission loss $+w_{b} *$ battery loss $+\left(w_{c l}+\right.$ $w_{c 2}($ current SOC - final SOC) $) *$ battery recharging loss 
where $w_{e}, w_{m}, w_{t}, w_{b}, w_{c l}$ and $w_{c 2}$ are weight factors defined by user. The initial values of $w_{e}, w_{m}, w_{t}$, and $w_{b}$ are set to 1.0. The $w_{c l}$ is the weight factor for battery recharging base and set to 1.70 and 1.97 respectively in the urban and highway driving cycle. The $w_{c 2}$ is the weight factor for battery recharging slope and set to -3.0 . The loss of each component is defined as:

Engine loss $=($ fuel power in $)-($ engine mechanical power out $)$ $\cdots$

Electric machine loss $=$ sum of losses of all motors in the system ...

Transmission loss $=$ gear mesh, spin and pumping loss of transmission ...

Battery loss $=I_{b a t}^{2} * r_{b a t} \ldots$

Battery recharging loss $=I_{b a t} * V_{b a t} \ldots$

The battery recharging loss is a measure of the fuel energy required to replace energy removed from the battery. If the battery assists the engine in propelling the vehicle at a given time, engine power is reduced but this represents a debit that must be returned to the battery.

The simulated fuel economy is $35.4 \mathrm{mpg}$ (6.64 liter/ $100 \mathrm{~km})$ in urban $(59.7 \%$ improvement) and $29.8 \mathrm{mpg}$ (7.89 liter $/ 100 \mathrm{~km})$ in highway $(5.8 \%$ improvement $)$, which results in $32.7 \mathrm{mpg}$ (7.19 liter/100km) composite fuel economy (32.8\% improvement). The predicted vehicle performance is: $176.2 \mathrm{kph}$ vehicle top speed, $5.7 \mathrm{~m} / \mathrm{s}^{2}(0.58 \mathrm{~g})$ peak acceleration, $0.7 \mathrm{sec}$ to peak acceleration, $4.1 \mathrm{sec}$ to reach 48 $\mathrm{kph}, 12.4 \mathrm{sec}$ to reach $96 \mathrm{kph}, 14 \mathrm{sec}$ to reach $128.7 \mathrm{kph}$ from $80.5 \mathrm{kph}$, and $13.1 \%$ gradeability at $88.5 \mathrm{kph}$.

\subsection{Two-Mode EVT Analysis}

The engine and final drive ratio are identical to conventional vehicle. The hybrid components include two inverters, battery (300 Volt, 6.5 amp-hrs, $20 \mathrm{~kW} \max$ power charge and $28 \mathrm{~kW}$ max power discharge), two electric machines $(25.1 \mathrm{~kW}$ rated power, $14000 \mathrm{rpm}$ rated speed, and $90 \mathrm{~N}-\mathrm{m}$ rated torque), three planetary gear sets and four clutches. The planetary gear ratios (ring gear teeth number / sun gear teeth number) are selected as: planetary gears one and two is 1.9545; planetary gear three is 2.6923 . The simulated fuel economy is $36.3 \mathrm{mpg}$ in urban $(63.5 \%$ improvement) and $29.5 \mathrm{mpg}$ in highway (4.6\% improvement), which results $32.9 \mathrm{mpg}$ combined fuel economy (33.7\% improvement). The predicted vehicle performance is: $192.7 \mathrm{kph}$ vehicle top velocity, $5.03 \mathrm{~m} / \mathrm{s}^{2}(0.51 \mathrm{~g})$ peak acceleration, 0.6 sec to peak acceleration, $3.2 \mathrm{sec}$ to reach $48 \mathrm{kph}, 9.4 \mathrm{sec}$ to reach $96 \mathrm{kph}, 8.2 \mathrm{sec}$ to reach $128.7 \mathrm{kph}$ from $80.5 \mathrm{kph}$, and $19.8 \%$ gradeability at $88.5 \mathrm{kph}$.

\section{OPTIMIZATION OF ELECTRIC MACHINE SIZE}

An electric machine delivers high torque at low speeds and high power at high speeds. These speed torque characteristics of the electric machine are ideally suited for traction function of the ground vehicles. The motor gives a constant torque for variable speed up to the 'base (rated) speed' of the motor; beyond the base speed, the torque of the motor decreases with increase in the speed. The main requirement that is related to the electric propulsion control is the ability to operate at constant power over a wide speed range, good overload performance, and high efficiency.

The objective of this paper is to optimize the traction motor in HEV to increase the fuel economy on an urban driving cycle. The vehicle fuel economy and performance data of two mild and three strong hybridization propulsions on front-wheel-drive vehicles are initially predicted using GT-Drive software. Using the simulated vehicle performance data (max. velocity, max. acceleration, and time to reach $96 \mathrm{kph}$ vehicle speed) as constraints and the motor rated torque and speed as the design variables, the objective function is to maximize the urban fuel economy. The objective function only targets on the urban driving cycle because most of the HEVs gain the fuel economy improvement mainly from the urban or city driving cycle. The urban or city driving cycle consists of stop-start operations and lower vehicle speed using electric launch. A completed design exploration software, iSight platform optimization algorithm $[29,30]$, is integrated with the GT-Drive for optimization study.

The basic overview of the integration process between the two software is described as (1) GT-Drive is used to build the vehicle model, make parameters of the independent variables, and run the model; (2) iSight is used to parse the independent parameters in the GT-Drive .dat file, parse the output variables in the GT-Drive .rlt file, and set up the command line execution of the GT-Drive. After choosing a strategy in the iSight, the model is ready to be executed. The iSight reads the output variables from the .rlt file at the end of each iteration and then replaces the independent variables in the .dat file before the next iteration begins.

The optimization problem statement is to size the motor in a manner that minimizes fuel consumption while meeting performance characteristics for a given driving cycle. Using a strong C-ISG hybrid vehicle as an example, the problem statement is described below.

Maximize: $F E_{u}$, Urban fuel economy (average mile per gallon of gasoline from all initial SOC load cases)

Subject to:

$t_{1} \leq 9.9 \mathrm{sec}$ (accelerate time to $96 \mathrm{kph}$ from 0$) \ldots$

$t_{2} \leq 10.4 \mathrm{sec}$ (accelerate time to $128.7 \mathrm{kph}$ from $80.5 \mathrm{kph}$ or quarter-mile acceleration) ...

$S_{\text {top }} \geq 178 \mathrm{kph} \ldots$

$a_{\max } \geq 3.5 \mathrm{~m} / \mathrm{s}^{2} \ldots$

By varying design variables:

$M_{t}$ (motor rated torque)

$M_{s}$ (motor rated speed)

With:

$S O C_{u}=0.68$, upper SOC limit ...

$S O C_{l}=0.52$, lower SOC limit ...

$S O C_{b}=\{0.52,0.60$, and 0.69$\}$ (multiple initial SOC load cases) 
Using the above simulated performance data $\left(S_{t o p} \geq 180\right.$ $\left.\mathrm{kph} ; a_{\max } \geq 3.5 \mathrm{~m} / \mathrm{s}^{2} ; t_{1} \leq 10 \mathrm{sec}\right)$ as constraints and the motor

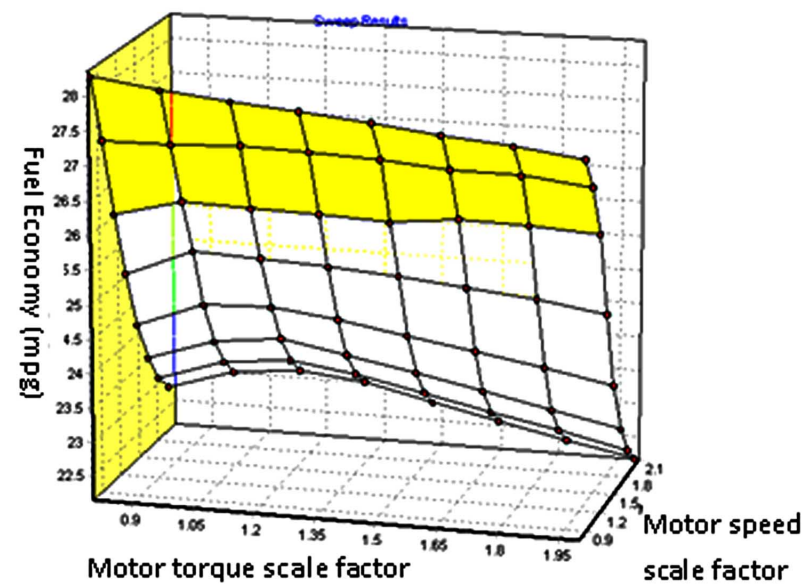

(a) B-ISG

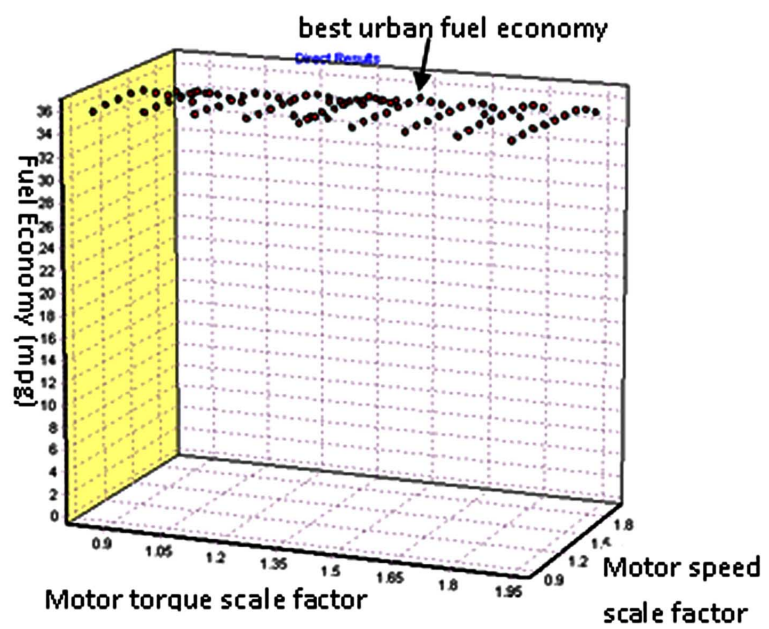

(c) Strong C-ISG rated torque and speed as the design variables, the objective function is to maximize the urban fuel economy. For a strong

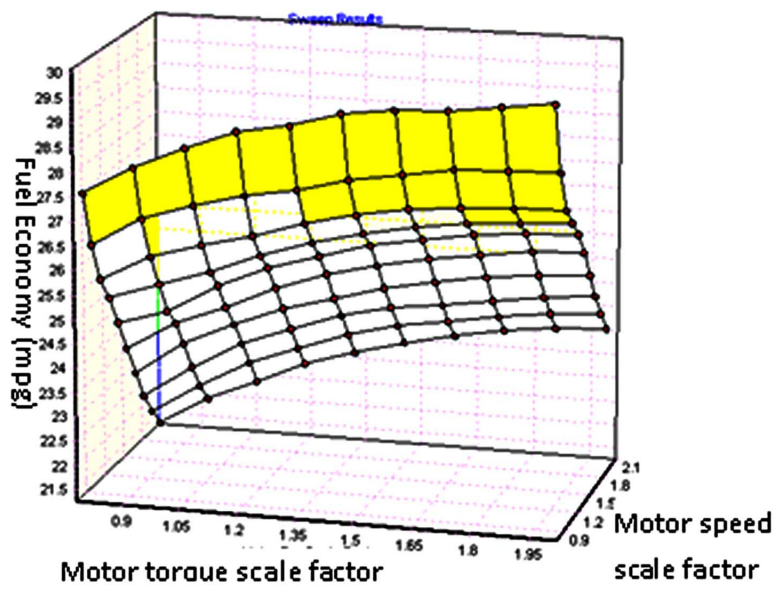

(b) Mild C-ISG

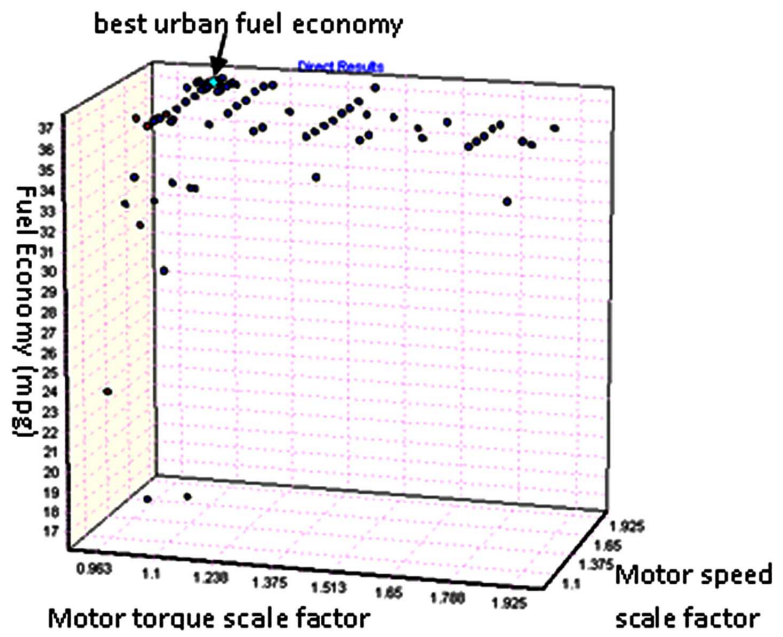

(d) One-mode EVT

(e) Two-mode EVT



Fig. (5). Optimization results of two mild and three strong hybrid configurations. 
Table 1. Summary of Simulation Results

\begin{tabular}{|c|c|c|c|c|c|c|c|c|}
\hline & & \multicolumn{6}{|c|}{ Fuel Economy (mpg) } & \multirow{2}{*}{$\begin{array}{c}\text { Performance (sec) } \\
0 \sim 96 \mathrm{kph}\end{array}$} \\
\hline & & Composite & $\%$ gain & Urban & $\%$ gain & Highway & $\%$ gain & \\
\hline \multicolumn{2}{|c|}{ Conventional } & 24.6 & & 22.2 & & 28.2 & & 9.6 \\
\hline \multirow[t]{2}{*}{ Mild HEV } & B-ISG & 26.0 & $5.7 \%$ & 24.3 & $9.4 \%$ & 28.4 & $0.7 \%$ & 10.2 \\
\hline & Mild C-ISG & 26.6 & $8.2 \%$ & 25.0 & $12.6 \%$ & 28.7 & $1.8 \%$ & 10.1 \\
\hline \multirow[t]{2}{*}{ Strong HEV } & Strong C-ISG & 30.9 & $25.5 \%$ & 32.7 & $47.2 \%$ & 28.9 & $2.5 \%$ & 9.9 \\
\hline & Two-mode EVT & 32.9 & $33.7 \%$ & 36.3 & $63.6 \%$ & 29.5 & $4.6 \%$ & 9.4 \\
\hline
\end{tabular}

Table 2. Summary of Simulation Results with Optimal Traction Motor Sizes

\begin{tabular}{|c|c|c|c|c|c|c|}
\hline & & \multicolumn{3}{|c|}{ Optimal traction motor size } & \multicolumn{2}{|c|}{ Fuel economy (mpg) } \\
\hline \multicolumn{2}{|c|}{ Conventional } & & & & 22.2 & \\
\hline \multirow[t]{2}{*}{ Mild HEV } & B-ISG & 6 & 13000 & 84 & 25.5 & $14.9 \%$ \\
\hline & Mild C-ISG & 10 & 14000 & 120 & 26.4 & $18.9 \%$ \\
\hline Strong HEV & Two-mode EVT & 56 & 17500 & 162 & 37.2 & $67.6 \%$ \\
\hline
\end{tabular}

C-ISG configuration, the optimal motor size $(26 \mathrm{~kW}$ rated power, $11620 \mathrm{rpm}$ rated speed, and $135 \mathrm{~N}-\mathrm{m}$ rated torque) results in a maximum urban fuel economy at $33.1 \mathrm{mpg}$ which is $49 \%$ improvement.

The same approach is applied to the other hybrid configurations to determine the optimal electric machine size. The optimal B-ISG motor size $(6.0 \mathrm{~kW}$ rated power, $13000 \mathrm{rpm}$ rated speed, and $84 \mathrm{~N}-\mathrm{m}$ rated torque) results in a maximum urban fuel economy at $25.5 \mathrm{mpg}$ which is $14.9 \%$ improvement while sustaining the vehicle performance. An optimal mild C-ISG motor size (10 kW rated power, $14000 \mathrm{rpm}$ rated speed, and $120 \mathrm{~N}-\mathrm{m}$ rated torque) results in a maximum urban fuel economy at $26.4 \mathrm{mpg}$ which is $18.9 \%$ improvement while sustaining the vehicle performance. For the strong hybrid configurations, the front axle optimal motor size $(26 \mathrm{~kW}$ rated power, $16786 \mathrm{rpm}$ rated speed, and $92 \mathrm{~N}$ $\mathrm{m}$ rated torque) results in a maximum urban fuel economy at $33.4 \mathrm{mpg}$ which is $50.5 \%$ improvement while sustaining the vehicle performance. The optimal motor size $(41 \mathrm{~kW}$ rated power, $21238 \mathrm{rpm}$ rated speed, and $97 \mathrm{~N}-\mathrm{m}$ rated torque) for a one-mode EVT results in a maximum urban fuel economy at $36.7 \mathrm{mpg}$ which is $65.3 \%$ improvement. In the two-mode EVT, the optimal motor size $(56 \mathrm{~kW}$ rated power, $17500 \mathrm{rpm}$ rated speed, and $162 \mathrm{~N}-\mathrm{m}$ rated torque) results in a maximum urban fuel economy at $37.2 \mathrm{mpg}$ which is $67.6 \%$ improvement. Figs. (5a) and (5b) respectively show the optimization results for B-ISG mild C-ISG. Figs. (5c) to (5e) show the optimization results for three strong hybrid propulsion configurations.

Simulation results are summarized in Table 1, indicating that mild and strong hybrid configurations can result in urban fuel economy gains respectively up to $12.6 \%$ and $63.6 \%$ over conventional powertrain. Using the simulated vehicle performance data (top speed, maximum acceleration and time to reach $96 \mathrm{kph}$ vehicle speed) as constraints and the motor rated torque and speed as the design variables, the objective function is to maximize the urban fuel economy. Since the main fuel economy gains is in the urban driving cycle and the electric motor plays an important role in improving urban fuel economy, the optimal motor sizes are investigated only in the urban cycle. Table 2 summarizes the optimal motor size and maximum urban fuel economy for five hybrid configurations. The purpose of this study is to provide a design guideline for hybrid propulsion configuretions and component sizing of the traction motors.

\section{CONCLUSIONS}

This paper presents the modeling and simulation of vehicle fuel economy and performance for two mild and three strong hybridization propulsions on front-wheel-drive vehicles. Based on the simulation results, the traction motor sizes, by means of motor rated torque and speed, are optimized for maximum urban fuel economy. The two mild hybrids are B-ISG and C-ISG systems. The three strong hybrid configurations include a strong C-ISG system where motor is placed between a starting clutch and the transmission, one-mode and two-mode EVTs. The main fuel economy improvement is in the urban driving cycle, this is due to (1) allowing the engine to shut-off under vehicle coastdown and stop conditions, and (2) launching vehicle by electric motor. In order to keep the same towing capability as conventional vehicle, engine downsizing advantage was not 
adopted. If a smaller engine were implemented, the fuel economy improvements would be larger.

The significant packaging change to accommodate the increased envelope of the optimal electric motor and the corresponding battery are not taken as the constraints in the optimization process. It would be difficult to pack two electric motors and planetary gear sets (an EVT system) in a small or compact front-wheel-drive vehicle. The optimal motor size might not be feasible in the actual design and manufacturing stage. This study does not investigate the driveability which could be a major issue for strong C-ISG configuration since torque converter is replaced by a starting clutch.

\section{ABBREVIATIONS}

$a_{\max }=$ Vehicle maximum acceleration

$F E_{u} \quad=\quad$ Urban fuel economy

$I_{\text {bat }} \quad=$ Battery current

$\mathrm{kph}=$ Kilo meters per hour

$\mathrm{kW}=$ Kilo Watts

$M_{t} \quad=\quad$ Motor rated torque

Ms $\quad=$ Motor rated speed

$\operatorname{mpg}=$ Miles per gallon

$\mathrm{N}-\mathrm{m}=$ Newton-meter

$\mathrm{rpm}=$ Revolutions per minute

$r_{\text {bat }}=$ Battery resistance

SOC $=$ State Of Charge on battery

$S_{u}=$ Upper SOC limit

$S_{l}=$ Lower SOC limit

$S O C_{b}=$ Initial SOC load cases

$S_{\text {top }} \quad=\quad$ Vehicle top speed

$t_{1}=$ Accelerate time to $96 \mathrm{kph}$ from 0

$t_{2}=$ Accelerate time to $128.7 \mathrm{kph}$ from $80.5 \mathrm{kph}$ or quarter-mile acceleration

$V_{\text {bat }}=$ Battery voltage

$w_{b} \quad=$ Weight factor of battery loss

$w_{c l}=$ First weight factor of battery charging loss

$w_{c 2}=$ Second weight factor of battery charging loss

$w_{e} \quad=$ Weight factor of engine loss

$w_{m} \quad=$ Weight factor of electric machine loss

$w_{t} \quad=$ Weight factor of transmission loss

\section{ACKNOWLEDGEMENTS}

This work was supported in part by the National Science Foundation, CCLI-Phase I: Exploratory, under grant number DUE-0941809.

\section{CONFLICT OF INTEREST}

None declared.

\section{REFERENCES}

[1] K.T. Chau, and S. Wong, "Overview of power management in hybrid electric vehicles", Energ. Convers. Manage., vol. 43, pp. 1953-68, 2002

[2] K. Oh, J. Min, D. Choi, and H. Kim, "Optimization of control strategy for a single-shaft parallel hybrid electric vehicle", IMechE Proc. Part D: J. Automob. Eng., vol. 221, 2007, pp. 555-65.

[3] Y. Zhang, H. Lin, B. Zhang, and C. Mi, "Performance modeling and optimization of a novel multi-mode hybrid powertrain", ASME Trans. J. Mech. Des., vol. 128, pp. 79-89, 2006.

[4] M. Zeraoulia, M. Benbouzid, and D. Diallo, "Electric motor drive selection issues for HEV proulsion systems: a comparative study", IEEE Trans. Veh. Technol., vol. 55, no. 6, pp. 1756-64, 2006.

[5] M. Ehsani, Y. Gao, and S. Gay, "Characterization of electric motor drives for traction applications", In: IEEE annual conference, vol. 1, 2003, pp. 891-6.

[6] Y.G. Liao, T. Weber, and D. Pfaff, "Modeling and analysis of powertrain hybridization on all-wheel-drive sport utility vehicles", IMechE Proc. Part D: J. Automob. Eng., vol. 218, pp. 1125-34, 2004

[7] E. Odvarka, A. Mebarki, D. Gerada, N. Brown, and C. Ondrusek, "Electric motor-generator for a hybrid electric vehicle", Eng. Mech., vol. 16, no. 2, pp. 131-39, 2009.

[8] H. Kusumi, K. Yagi, Y. Ny, S. Abo, H. Sato, S. Furuta, and M. Morikawa, "42V power control system for mild hybrid vehicle (MHV)", SAE paper 2002-01-0519, 2002.

[9] G. Tamai, M. Jeffers, C. Lo, C. Thurston, S. Tarnowsky, and S. Poulos, "Development of the hybrid system for the Saturn VUE hybrid", SAE paper 2006-01-1502, 2006.

[10] M. Canova, K. Sevel, Y. Guezennec, and S. Yukovich, "Control of the start/stop of a diesel engine in a parallel HEV with a belted starter/alternator", SAE paper 2007-24-0076, 2007.

[11] D. Evans, M. Polom, S. Poulos, K. VanMaanen, and T. Zarger, "Powertrain architecture and controls integration for GM's hybrid full-size pickup truck", SAE paper 2003-01-0085, 2003.

[12] X. Chen, and S. Shen, "Comparison of two permanent-magnet machines for a mild hybrid electric vehicle application", SAE paper 2008-01-1552, 2008.

[13] K. Hanada, M. Kaizuka, S. Ishikawa, T. Imai, H. Matsuoka, and H. Adachi, "Development of a hybrid system for the V6 midsize sedan", SAE paper 2005-01-0274, 2005.

[14] A. Kabasawa and K. Takahashi, "Development of the IMA motor for the V6 hybrid midsize sedan”, SAE paper 2005-01-0726, 2005.

[15] C. Lin, H. Peng, J. Grizzle, J. Liu, and M. Busdiecker, "Control system development for an advanced-technology medium-duty hybrid truck", SAE paper 2003-01-3369, 2003.

[16] L. Tsai, G. Schultz, and N. Higuchi, "A novel parallel hybrid transmission", ASME Trans. J. Mech. Des., vol. 123, pp. 161-8, 2001

[17] K. Ahn, S. Cho, S. Cha, and J. Lee, "Engine operation for the planetary gear hybrid powertrain", IMechE Proc. Part D: J. Automob. Eng., vol. 220, pp. 1727-35, 2006.

[18] S. Cho, K. Ahn, and J. Lee, "Efficiency of the planetary gear hybrid powertrain", IMechE Proc. Part D: J. Automob. Eng., vol. 220, pp. 1445-54, 2006.

[19] D. Zhang, J. Chen, J. Hsieh, J. Rancourt, and M. R. Schmidt, "Dynamic modelling and simulation of two-mode electric variable transmission", IMechE Proc. Part D: J. Automob. Eng., vol. 215, pp. 1217-23, 2001

[20] G. Tamai, S. Reeves, and T. Grewe, "Truck utility and functionality in the GM 2-mode hybrid", SAE paper 2010-01-0826, 2010 .

[21] Toyota Hybrid System THSII, Toyota Motor Corporation, Public Affairs Division, 2003. [Online] Available: http://www.evworld. com/library/ toyotahs2.pdf [Accessed May 11, 2011].

[22] J. Meisel, "An analytical foundation for the Toyota Prius THS-II powertrain with a comparison to strong parallel-electric powertrain", SAE paper 2006-01-0666, 2006.

[23] M.R. Schmidt, "Two-mode, input-split, parallel, hybrid transmission", U. S. Patent 5,558,588, September 24, 1996. 
[24] GT-Drive, Gamma Technologies, Inc., Westmont, IL, USA: [Online] Available: http://www.gtisoft.com/. [Accessed May 25, 2011].

[25] S. Hausberger, and M. Rexeis, "Emission behaviour of modern heavy duty vehicles in real world driving", Intl. J. Environ. Pollut., vol. 22 , no. 3, pp. 275-86, 2004.

[26] M. Ward, C. Brace, T. Hale, and R. Ceen, "Investigation of sweep mapping approach on engine testbed", SAE paper 2002-01-0615, 2002.

[27] U.S. Environmental Protection Agency (EPA), Testing and Measuring Emissions: [Online] Available: http://www.epa.gov/ fueleconomy/420f06069. htm\#background_existing. [Accessed June 6, 2011].

[28] G. Paganelli, T.M. Guerra, S. Delprat, J. Santin, M. Delhom, and E. Combes, "Simulation and assessment of power control strategies for a parallel hybrid car", IMechE Proc. Part D: J. Automob. Eng., vol. 214, pp. 705-17, 2004.

[29] B. Tillock, and C. Yuan, "iSIGHT/GT-Power coupling: brake torque design exploration with constrained knock index and NOx", In: GT-Suite Conferences, Frankfurt: Germany, 2008.

[30] Isight, Dassault Systems Simulia Inc., Providence, RI, USA: [Online] Available: http://www.simulia.com/products/isight.html. [Accessed Apr. 5, 2011].

(C) Liao et al.; Licensee Bentham Open.

This is an open access article licensed under the terms of the Creative Commons Attribution Non-Commercial License (http: //creativecommons.org/licenses/by$\mathrm{nc} / 3.0 /$ ), which permits unrestricted, non-commercial use, distribution and reproduction in any medium, provided the work is properly cited. 